\title{
Research On The Construction Of Scientific And Technological Service Mode And Service Platform Based On O2O
}

\author{
Shengju Yang ${ }^{1}$, Jianbing Wei ${ }^{*}$, Jie Meng ${ }^{1}$, Dekui $\mathrm{Lv}^{2}$ \\ 1. Institute of Scientific \& Technical Information of Gansu, Key Laboratory of Scientific \& Technical Evaluation and \\ Monitoring of Gansu, Gansu Lanzhou 730000 \\ * Gansu Forestry Technological College, Gansu Tianshui 741020 \\ 2. The 28th Research Institute of China Electronics Technology Group Corporation, Nanjing 210000, China \\ * is corresponding author
}

Keywords: O2O business model, technological service, Keju website

\begin{abstract}
The interaction between the virtual world on the Internet and the off-line real life gives birth to a new business model- the $\mathrm{O} 2 \mathrm{O}$ business model. This paper expounds the relevant theory of $\mathrm{O} 2 \mathrm{O}$ mode, analyzes the relevant literature and advances some ideas about the scientific and technological service mode based on $\mathrm{O} 2 \mathrm{O}$ in view of the problems in technology service industry. Taking the case of Keju website as an example, the paper introduces the construction of the scientific and technological service mode based on $\mathrm{O} 2 \mathrm{O}$, the function of $\mathrm{O} 2 \mathrm{O}$ technology service platform and the closedloop process. At last, the development of the scientific and technological service mode based on $\mathrm{O} 2 \mathrm{O}$ in China is summarized.
\end{abstract}

\section{Introduction}

With the rapid development of Internet information technology, there been more frequent interaction between real life and the Internet and the network has increasingly become our important information platform. Under such circumstances, life service keeps moving towards mobile Internet. Based on the Internet, the interaction between the online virtual world and the offline real life has given birth to a new business model, that is, the $\mathrm{O} 2 \mathrm{O}$ business model ${ }^{[1]}$.

In the 2015 government work report, Premier Li Keqiang proposed to " take the Internet as the carrier and boom the emerging offline and online consumption ${ }^{[2]}$ ". This was the first time that Chinese Premier had suggested to encourage o2o online and offline consumption, which signifies that the Chinese o2o era has arrived.

\section{Review of $\mathrm{O} 2 \mathrm{O}$ model theory}

\subsection{Definition of $\mathrm{O2O}$ model}

O2o stands for "Online To Offline", which refers to combining offline business opportunities with the Internet and making the Internet the front line of offline transactions in order to facilitate the enterprise to attract customers online. This $\mathrm{O} 2 \mathrm{O}$ concept was first formally put forward by the founder and CEO of TrialPay AlexRampell in August 2011 in a guest article in TechCrunch, who found that the companies like Groupon, OpenTable and SpaFinder were all committed to the development of online and offline business model. The core of his $\mathrm{O} 2 \mathrm{O}$ business model is to look for consumers on the Internet, and then take them to the real store ${ }^{[3]}$.

$\mathrm{O} 2 \mathrm{O}$ model combines offline business opportunities and the Internet together, in which the Internet plays the role of advertising platform and trading platform and offline products or services spread through the Internet. Therefore, the customers can enjoy the more easier and quicker services.

\subsection{0 model application and precedures ${ }^{[4]}$}

The application of O2Omodel means service providers publish online products information and consumers consume off-line after online ordering and online payment. This involves three roles, namely, the online platform manager, service providers and consumers. The basic procedures include the following. Consumers order services online and pay online. After the online management platforms receive payment, they provide consumers the unique identification code SMS (or two-dimensional code SMS), with which consumers can enjoy the corresponding service after verification by professional equipment. The successful verification means that the transaction has been completed and the online platform will transfer the payment to the service provider. If consumers do not consume and want a refund, they can apply for a refund from the online management platform in accordance with the provisions.

\subsection{Advantages of $\mathrm{O} 2 \mathrm{O}$ model ${ }^{[5-6]}$}

The o2o model can help the offline businesses get more potential consumers and improve the collection of user consumption data through the online platform and then achieve precision marketing. In addition to saving the logistics costs, this model can also help to directly calculate, analyze, track and evaluate the marketing effect of businesses, which evades the unpredictability of the traditional marketing 
model. For the consumers, O2o model provides them comprehensive, timely, rich and suitable business discount information, which enables them to select and order products or services more efficiently and obtain relatively cheaper price than the offline consumption. This also greatly improves the user experience. For the platform, the $\mathrm{O} 2 \mathrm{O}$ model can bring high viscosity consumers and has a strong promotion effect and measurable promotion effect for business, which can attract a large number of offline life service businesses to join. Additionally, $\mathrm{O} 2 \mathrm{O}$ model can also achieve the alliance of different businesses.

\subsection{0 closed loop}

$\mathrm{O} 2 \mathrm{O}$ refers that the two $\mathrm{O}$ (Online and Offline) must achieve docking and recycling, which means that the online customers are guided to the offline line consumption to achieve the transaction, and then return to the online registration and feedback. The docking of the closed loop $\mathrm{O} 2 \mathrm{O}$ is to use the platform to integrate businesses, user information and payment channels to build the foundation for the inner loop recycling. The closed loop not only docks the online and offline channels and connects the users, businesses, and even the platform together, but also injects power to the loop so that businesses and users circulate like water. Therefore, in the formation of closed loop, docking is only the first step, while the recycling is the key. Closed loop is a basic attribute of the $\mathrm{O} 2 \mathrm{O}$ platform, which distinguishes $\mathrm{O} 2 \mathrm{O}$ platform from common information platforms.

\section{Problems existing in the science and technology service industry of Gansu province}

Compared with the developed provinces of the science and technology service industry, the science and technology service industry of Gansu province is characterized by the small scale of service organization, the poor service demand docking and the insufficient innovation of service model. It can't meet the needs of economic and social development in Gansu province and lags behind the needs of modern science and technology services industry, which are reflected in the following three aspects

3.1 Uneven distribution of science and technology service resources and urgent need for resource supply and demand docking

The science and technology information resources sharing of Gansu province has formed a relatively complete system, which brings together various resources, such as R \& D services, achievements transfer, intellectual property, and inspection and testing. The construction of sharing platform has also made some achievements. But there is an uneven distribution of resources among different regions. The scientific and technological resources mainly exist in some suburban areas in Lanzhou, Tianshui and Baiyin, etc. Furthermore, there are no mutual interaction and cohesive force between government and enterprises, enterprises and enterprises, enterprises and research institutions. They are lack of the awareness of integration and optimization of the resources allocation. Therefore, there is urgent need for the docking of resource supply and demand.

\section{2 small scale of science and technology service institutions and limited ability in market development}

At present, the science and technology service institutions of Gansu province are small. Furthermore, most of the science and technology service institutions are not known to the individual and enterprise users. Therefore, the service demand clients may have the problems of being unable to find the appropriate service providers, unclear description of needs and not meeting the needs, which limits the market development ability of science and technology services.

3.3 Restriction of traditional offline technology service industry on the development of science and technology service information

The traditional service means of science and technology service industry of Gansu province is mainly providing technical consulting service. This offline service is not sensitive to the change of market, weak in market competition and low in service ability and efficiency, thereby constraining the expansion of the ability of science and technology service. In view of the above problems, it is urgent to study the innovation of science and technology service model and promote the development of science and technology service industry by using the benefit sharing mechanism of marketization as the link and integrating quality technology service resources. With the rapid development of cloud computing, Internet of things, big data, mobile Internet, the scientific and technological service channels need to be widened and the online and offline integrated innovation service model should be developed to build science and technology service model based on o2o mode.

\section{4 science and technology service model based on 020}

\section{1 connotation}

Science and technology service industry upstream and downstream of the science and technology resources on the basis of $\mathrm{O} 2 \mathrm{O}$ cater to local customers, integration and docking, changes traditional service providers to provide a single service mode of the status quo, construct a customer oriented integrated service mode.

\section{2 construction}

Science and technology service model based on $\mathrm{O} 2 \mathrm{O}$ provides scientific and technological resources to gather, docking, so as to integrate the upstream and downstream technology resources of the service chain. Figure 1 shows the framework of the $\mathrm{O} 2 \mathrm{O}$ based service model of science and technology. 


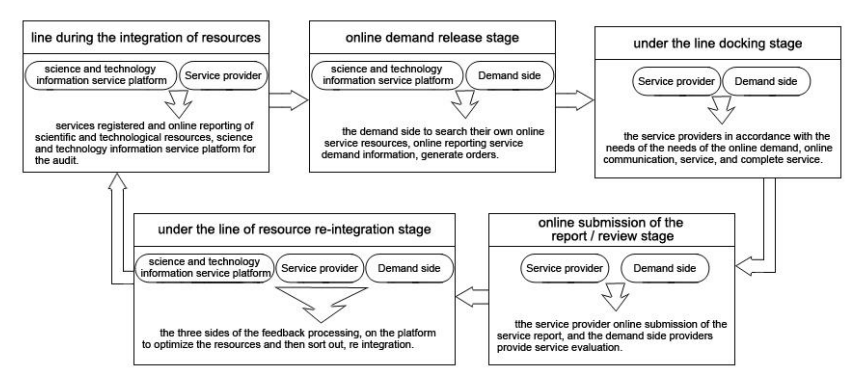

Figure 1 framework of $\mathrm{O2O}$ based service model for science and technology

(1) line during the integration of resources, services registered and online reporting of scientific and technological resources, science and technology information service platform for the audit, and in accordance with the construction of the science and technology service directory, directory service within the scope of a science and technology service resources together, integration, resource service including service agencies and service products.

(2) online demand release stage, the demand side to search their own online service resources, online reporting service demand information, generate orders.

(3) under the line docking stage, the service providers in accordance with the needs of the needs of the online demand, online communication, service, and complete service, and at this time, the demand side needs to be delivered to service funds.

(4) online submission of the report / review stage, the service provider online submission of the final results of the service report, to prove the reliability of the service results; and the demand side needs to be submitted to the service providers to provide service evaluation.

(5) under the line of resource re-integration stage, the demand side and service platform for the demand side of the two sides of the feedback processing, on the platform to optimize the resources and then sort out, re integration.

From the technology framework of $\mathrm{O} 2 \mathrm{O}$ service model based on the framework, completed from the line to the service line under closed loop. The author believes that the $\mathrm{O} 2 \mathrm{O}$ loop is a combination of the key factors to enhance industrial efficiency. $\mathrm{O} 2 \mathrm{O}$ service model is a combination of online and offline, and in order to give users a better experience, namely the $\mathrm{O} 2 \mathrm{O}$ service model is the line under the demand side / service providers and technology service platform more closely together, so that science and technology service platform to become their front line deal. The line of idle resources of science and technology through science and technology service platform aggregation, especially local service institutions of science and technology resources, pushed to the demand side, let the demand side online, then online the consumer experience, to complete the transaction, to form a closed loop.

\section{Based on the function of 020 technology service platform}

According to the above proposed $\mathrm{O} 2 \mathrm{O}$ based technology services model framework, in view of the various stages of the framework to provide services to the Department of poly network as an example, a detailed introduction of the main functions of science and technology services platform.

\section{1 section poly Network Introduction}

Families get together the net is Gansu Province Science and Technology Information Institute of Gansu Provincial Science and Technology Department of guidance, integration of universities, research institutes, engineering technology research center, Key Laboratory, high technology enterprises more than 600 units to for enterprises and institutions to provide scientific instruments and facilities, scientific and technical literature, inspection and testing, research and development, technology transfer business incubation, technology consulting, intellectual property, technology and financial services online and offline one-stop research and innovation collaborative services platform. Families get together the net is in Gansu Province the first sponsored by the government the $\mathrm{O} 2 \mathrm{O}$ mode of science and technology business platform.

\subsection{Main functions of the branch network}

Polymer network publishing platform for technical problems into fancy poly, poly mesh in $\mathrm{O} 2 \mathrm{O}$ service, online trading platform is mainly "match", and more service is online. A poly mesh efforts to build open resources docking platform for the industry of scientific research management to enhance the productivity of scientific and technological innovation to create the best online and offline resources docking. For colleges and universities, research institutions, "science" is a showcase achievements in scientific research platform, the project by the enterprise, they may hatch industry. For the enterprise, "together" is a solution to the enterprise, the enterprise technical requirements, the relevant domain experts can help enterprises to solve the technical problems. The main function is as follows.

(1) the service catalog filtering function

Selection of directory service is refers to $\mathrm{O} 2 \mathrm{O}$ mode framework of line resource integration stage by the integration of the science and technology resources, in accordance with the use of directory service technology development service directory classified display. Users in the directory service selection related industries or services classification and demand side can quickly locate the services they need, and service providers can also quickly find you can solve the problem, which can efficiently for demand side and service provider brings benefit.

(2) release function of science and technology resources

Resources of science and technology publishing stage is published in $\mathrm{O} 2 \mathrm{O}$ mode framework of online information and service providers in the science and technology information service platform for the release and its service related information, including information and technology services and products information, improve their own exposure to obtain more orders.

\section{(3) demand release function}

Demand release function is in the $\mathrm{O} 2 \mathrm{O}$ mode framework of the online demand release stage, the demand side in the 
science and technology service platform with a free release service demand function, the use of $\mathrm{O} 2 \mathrm{O}$ in Online solicit customers way, in the scientific and technological service platform to find solutions to the needs of the service providers.

\section{(4) the results of the report submitted to the function}

Results report function is in $\mathrm{O} 2 \mathrm{O}$ mode framework of online reporting stage, after the completion of the docking services online service providers and demanders, service providers need to submit a report on the outcome in the science and technology service platform, in order to prove the effective completion of the science and technology service. Service providers of the service is to be recognized, depends to a large extent to report the results of whether effectively solves the demand side, whether to have the professional and scientific.

(5) comment function

After the comment function in $\mathrm{O} 2 \mathrm{O}$ mode framework of online submit review stage, demand side in to complete the line docking services and received from the service providers in the reporting of outcomes, the need for online service providers to the service evaluation, evaluation content will affect the reputation of the service provider.

\subsection{Closed loop process of $\mathbf{O 2 O}$ service model}

Department of polymer network O2O service model of closed-loop process consists of four main parts: the first part is the online matchmaking, service providers through the Keju web site to show their products and services, the demand side is to obtain information technology products through online services, evaluation and selection; the second step is to generate orders, through online matchmaking, demand side in Keju online operation, to generate orders, families get together the net orders sent to the user's mobile phone digital certificate of production order; the third link is the next line of consumer demand with the order digital certificates to offline service providers to the consumer to buy their own technology services; the fourth part is when the consumption is completed, the relevant consumer transactions the report will provide information and evaluation information to the background processing, on the one hand back to the service providers, on the other hand can be pushed to the demand side, the demand side to provide the basis for the next purchase.

\section{Concluding remarks}

With the development of e-commerce in China's rapid development, science and technology service industry from the maturity of e-commerce business model, as a commodity technology service, using the $\mathrm{O} 2 \mathrm{O}$ model for sales in the service platform, and achieved good results. Based on the science and technology service platform $\mathrm{O} 2 \mathrm{O}$ mode more influential is organized by the Tianjin City science and technology small and medium-sized enterprise development work leading group office of Amoy network, Xiamen Information Technology Co., the company created a net, the Xi'an Municipal Science and Technology Bureau and the Xi'an high tech Zone to build the Xi'an science and technology market, Guizhou province science and Technology Department of Guizhou province organized by the science and technology resources service platform, science and Technology Department of Gansu province organized by the Department of polymer network Beijing intellectual construction enterprise management consulting Co. Ltd., set net and so on.

\section{Acknowledgments}

This work is supported by Gansu Province Youth Science and Technology Fund Project(No. 1606RJYA304), all support is gratefully acknowledged.

\section{References}

[1]Zheng Zhongxiang.Herd Behavior Study in "O2O" Business Model[D]. Beijing Institute of Graphic Communication,2015

[2]

http://lianghui.people.com.cn/2015npc/n/2015/0305/c3942 98-26642056-5.html. 2015,03,05

[3]Cui Jian,Zhu Xiaodong.The Exploration of Factors Influencing Consumption Experience Based On the $\mathrm{O} 2 \mathrm{O}$ Model[J]. Journal of Modern Information,2014,12:55$59+63$.

[4]Li Cuizhi.The Advantages and Disadvantages of $\mathrm{O} 2 \mathrm{O}$ Mode in Electronic Commerce_- the Case of Nuomi[J]. Agriculture Network Information,2014,07:10-14.

[5]Hou Qiaohong.O2O new platform: How to take the enterprise[J]. China Marketing,2011,(8):101-103

[6]Chi Lian. On the opportunities and challenges faced by the $\mathrm{O} 2 \mathrm{O}$ model of electronic commerce[J]. Commercial Times, 2014,25:63-64.

[7]Zhang Bo. O2O mobile Internet era of business revolution[M].Bei Jing: China Machine Press,2013.

[8]Su Lixia,Wu Di,Li Mengmeng.Discussion on Cross-sector O2O Operation Mode for Logistics Enterprises[J]. Logistics Technology,2015, 05: 44-45.

[9]Guan Rongwei. Study on the Modes of Online to Oflfine for Clothing Retail Enterprises[J]. China Textile Leader, 2015, 01: 84-87.

[10]Liang Qingyu,Liu Zenglun. Research on the application of $\mathrm{O} 2 \mathrm{O}$ marketing mode in China's travel agency[J]. China Business \& Trade,2014,31: 72-73.

[11]Yang Hong.Feasibility study on the $\mathrm{O} 2 \mathrm{O}$ model of traditional retail enterprises $[\mathrm{J}]$. Commercial Times,2015,01: 69-70.

[12]Chen Jie. Research on the O2O Integrated Service Model Based Face to Technology Services[D]. Beijing Jiaotong University,2014. 